\title{
Selection of the main micronutrients for the production of biosurfactant by an isolated Bacillus subtilis strain
}

\author{
Mariana Ruiz Frazão Santiago, Vitor da Silva Liduino, Lizeth Jaramillo, Paula Fernandes de \\ Aguiar, Maria Aparecida de Melo, Eliana Flávia Camporese Sérvulo
}

\begin{abstract}
Biosurfactants possess various unique properties, such as good environmental compatibility, low toxicity, high selectivity, high biodegradability and are stable over a wide range of temperature, $\mathrm{pH}$ and ionic strengh. These advantages allow the substitution of chemically synthesized surfactants by those of biological origin in different industrial sectors, mainly for enhanced oil recovery. This study presents the influence of different micronutrients ( $\mathrm{B}, \mathrm{Fe}, \mathrm{Zn}, \mathrm{Cu}, \mathrm{Mn}, \mathrm{Ca}$, Mo and $\mathrm{Co}$ ) in biosurfactant production by Bacillus subtilis, LFB 732 strain, using very high polarization (VHP) raw sugar, as the one and only cost-effective carbon source. A Plackett-Burman design, with 12 tests, in replicate, was employed for screening eight mineral salts, which are regular constituents of fermentative medium, aiming to reduce the cost of the bioprocess. Batch fermentation experiments were carried out in shake-flasks at the controlled agitation speed of $150 \mathrm{rpm}$ and temperature of $30^{\circ} \mathrm{C}$, for 24 and $48 \mathrm{~h}$. The experimental data revealed that $\mathrm{Fe}$ and $\mathrm{Zn}$ ions were the most important micronutrients in the fermentation broth for production of this biosurfactant and the absence of the others did not affected the production.
\end{abstract}

Index Terms - Biosurfactant, Bacillus subtilis, VHP sugar, Plackett-Burman design, mineral salts medium.

\section{INTRODUCTION}

Biosurfactants, comparatively to the chemical surfactants available in the market, are amphiphilic molecules with similar surface-active properties [1]. In contrast, the biomolecules have a larger structural diversity compared to the non-biossyntetic products due to the possibility of production by a wide variety of microorganisms, including yeast, filamentous fungi and mainly bacteria [2].

Mariana Ruiz Frazão Santiago, Departamento de Engenharia Química, Universidade Federal do Rio de Janeiro, Rio de Janeiro, Brasil, +55-21-35967057/+55-21-964937904

Vitor da Silva Liduino, Departamento de Engenharia Química, Universidade Federal do Rio de Janeiro, Rio de Janeiro, Brasil, +55 987504811

Lizeth Jaramillo, Departamento de Engenharia Química, Universidade Federal do Rio de Janeiro, Rio de Janeiro, Brasil, +55-21-995260670

Paula Fernandes de Aguiar, Departamento de Química analítica, Universidade Federal do Rio de Janeiro, Rio de Janeiro, Brasil, +55-21-991223216

Maria Aparecida de Melo, Centro de Pesquisas Leopoldo Américo Miguez de Mello (Cenpes), Universidade Federal do Rio de Janeiro, Rio de Janeiro, Brasil, +55-21-998523010

Eliana Flávia Camporese Sérvulo, Departamento de Engenharia Química, Universidade Federal do Rio de Janeiro, Rio de Janeiro, Brasil, +55-21-999945770
The biomolecules present many advantages when compared to chemically synthesized surfactants, such as biodegradability, high selectivity, low toxicity and stability against environmental variations (temperature, $\mathrm{pH}$, ionic strength) [3]. Thus, biosurfactants became an environment-friendly alternative to chemical surfactants Also, the use of synthesized surfactants is not recommended due to its toxic effects on living organisms and on the environment, causing secondary pollution.

Bacillus species, in particular strains of Bacillus subtilis (non-pathogenic microorganism considered as GRAS generally considered as safe) are potential producers of different biosurfactants [4]. Many studies in the literature show that the main bio-product synthesized by $B$. subtilis is surfactin, a lipopeptide with interesting surface-active properties, foaming emulsifier and wetting agent, which allow its application in several industrial areas [5], such as in microbial enhanced oil recovery (MEOR) reducing the capillary forces that prevent the movement of the oil through the pores of the rock [6].

However, microbial surfactants are not yet widely used due to the high production costs, associated with inefficient methods of product recovery and the use of expensive substrates on the fermentative process. The economic production issue of biosurfactants can be significantly reduced with the use of alternative sources of nutrients [7]. One possible strategy is to apply renewable sources in the production medium composition, which can reduce production costs by up to $30 \%[8,9]$. Therefore, recent studies in this field aim at the use of industrial residues as nutrients in production medium and the optimization of the fermentation conditions seeking the best strategies for the production of microbial surfactants in large scale [10].

Thus, the present work emphasized the use of VHP (very high polarization) sugar as a carbon source for the production of the biosurfactant by a $B$. subtilis strain. The choice of VHP sugar as carbon source is justified because it is the raw form of refined sugar, thus representing less production costs. Also, this work evaluated the influence of reducing the addition of micronutrients in the production medium, since the composition of the culture media currently used by the industry covers a large quantity and variety of micronutrients In this way, it is expected to obtain

a low cost biosurfactant with higher economic feasibility for the application in the oil recovery.

This study was supported by Fundação de Amparo à Pesquisa do Estado do Rio de Janeiro. 


\section{MATERIALS AND METHODS}

\section{A) Microorganism}

The strain used was the Bacillus subtilis LFB 732 from the Bacillus Cultivation Collection and Correlated Genus/ Fiocruz maintained in Agar nutrient and stored at $4{ }^{\circ} \mathrm{C}$.

B) Quantification of the components content in VHP sugar

The chemical elements of the VHP sugar $(\mathrm{Ca}, \mathrm{Mg}, \mathrm{K}, \mathrm{Mn}$, $\mathrm{Fe}, \mathrm{Co}, \mathrm{Cu}, \mathrm{Zn}, \mathrm{S}$ and $\mathrm{P}$ ) were analyzed by inductively coupled plasma optical emission spectrometry (ICPOES) with the equipment Horiba Jobin Yvon, model Ultima 2. The calibration was done with appropriated standard solutions for each element. The procedure was adapted from the norm ASTM-D1976 Standard Test Method for Elements in Water by Inductively-Coupled Argon Plasma Atomic Emission Spectroscopy, usually applied for general aqueous samples. The VHP sugar used in this study was composed by $(\mathrm{mg} / \mathrm{kg})$ : $\mathrm{Ca}$ (34), $\mathrm{Mg}$ (14), K (52), Fe (0.83), Zn (0.23), Cu (<0.5), Mn $(<0.5), \mathrm{Co}(<0.5), \mathrm{P}(2), \mathrm{S}(27)$.

\section{C) Inoculum preparation}

The Bacillus subtilis LFB 732 was inoculated in Petri dishes containing Agar nutrient and incubated at $30^{\circ} \mathrm{C}$ for 24h. Thereafter, two loops of the activated culture were transferred to $500 \mathrm{~mL}$ Erlenmeyer flasks, containing $100 \mathrm{~mL}$ of nutrient medium containind $(\mathrm{g} / \mathrm{L})$ : meat peptone $(5)$, yeast extract (3), glucose (9) and $\mathrm{NaCl}(9)$, at $\mathrm{pH} 7$ and sterilized at $121^{\circ} \mathrm{C}$ for 15 minutes in the autoclave. The flasks were incubated in a rotary shaker (CIENTEC - 712 RN) at $150 \mathrm{rpm}$ and $30^{\circ} \mathrm{C}$. After the culture reached optical density (OD) of 0.3 at $600 \mathrm{~nm}$, ten milliliters of that inoculum was transferred to $100 \mathrm{ml}$ of the production media in Erlenmeyer flasks.

\section{D) Batch Fermentation}

All the assays were conducted in Erlenmeyer flasks of $500 \mathrm{ml}$ on a rotary shaker at $150 \mathrm{rpm}$ and $30^{\circ} \mathrm{C}$, with 100 $\mathrm{ml}$ of production medium, sterilized at $121^{\circ} \mathrm{C}$ for 15 minutes in the autoclave, and $5 \mathrm{ml} / \mathrm{L}$ of micronutrients solution, previously sterilized by filtration. The fermented medium was centrifuged at $15,300 \mathrm{~g}$ for 10 minutes to carry out the analytical determinations.

\section{E) Selection of the main micronutrients for the biosurfactant production}

A defined production medium was firstly prepared with the following composition $(\mathrm{g} / \mathrm{L})$ : $\mathrm{NH}_{4} \mathrm{NO}_{3}(4), \mathrm{KH}_{2} \mathrm{PO}_{4}(3)$, $\mathrm{Na}_{2} \mathrm{HPO}_{4}(6)$ e $\mathrm{MgSO}_{4}(0,2)$, and VHP sugar (10), adjusted to $\mathrm{pH}$ 7. A Plackett-Burman type planning (PB12) was carried out with the goal to select the micronutrient solution components added to the production medium that effect the biosurfactant production. The fermentations were carried out for 24 and 48 hours, and the biosurfactant concentration was used as the main evaluation criterion. A full first-order polynommial model was used to represent the adjustment of the response values:

$\mathrm{Y}\left(\mathrm{x}_{1}, \mathrm{x}_{2}, \mathrm{x}_{3}\right)=\mathrm{b}_{0}+\mathrm{b}_{1} \mathrm{x}_{1}+\mathrm{b}_{2} \mathrm{x}_{2}+\mathrm{b}_{3} \mathrm{x}_{3}+\mathrm{b}_{4} \mathrm{x}_{4}+\mathrm{b}_{5} \mathrm{x}_{5}+\mathrm{b}_{6} \mathrm{x}_{6}+$ $\mathrm{b}_{7} \mathrm{x}_{7}+\mathrm{b}_{8} \mathrm{x}_{8}$

Where: $Y=$ response estimation; $b=$ model coefficients; $\mathrm{x}=$ variables.

\section{F) $p H$}

The $\mathrm{pH}$ measurements were performed directly on cell-free fermented medium in the digital model DMPH-1 (Digimed).

\section{G) Surface Tension}

Surface tension was determined in the cell-free fermented broth using a tensiometer SIGMA 70 Surface tension measurement report (KSV Instruments Ltd) at $25^{\circ} \mathrm{C}$, according to the De Nouy ring method [11], using uninoculated media $(62,5 \mathrm{mN} / \mathrm{m})$ as abiotic negative controls.

\section{H) Biomass}

Cell growth was determined by measuring the optical density of the samples, using a Hach spectrophotometer (DR 5000) at $600 \mathrm{~nm}$. Cell concentration was determined using a calibration curve that related the values of optical density and dry weight [12].

\section{I) Biosurfactante concentration}

Biosurfactant concentration was determined using a high-performance-liquid chromatographer equipped with a UV detector (LC 10A- Shimadzu), at $205 \mathrm{~nm}$, and a Symmetry C18column (150 x $4.6 \mathrm{~mm}, 5 \mu \mathrm{m})$. The mobile phase consisted of $20 \%(\mathrm{v} / \mathrm{v})$ trifluoroacetic acid $(3.8 \mathrm{mM})$ and $80 \%(\mathrm{v} / \mathrm{v})$ acetonitrile. The elution rate was $1.0 \mathrm{~mL} / \mathrm{min}$ at $30^{\circ} \mathrm{C}$ and the sample size was $20 \mu \mathrm{L}$ [13]. The identity of the purified surfactin was obtained by using the commercially available $98 \%$ pure surfactin (Sigma-Aldrich) as the reference compound.

\section{RESULTS AND DISCUSSION}

The Plackett-Burman experimental design was done by analysing the eight variables $\left(\mathrm{x}_{1}\right.$ to $\left.\mathrm{x}_{8}\right)$ and the different levels of each variable (-1 and 1), as indicated in Table I.

Table I: Concentration values of the variables and their respective levels of the Plackett-Burman experimental design PB12.

\begin{tabular}{cccc}
\hline \multirow{2}{*}{ Variables } & Components & \multicolumn{2}{c}{ Levels $(\mathrm{g} / \mathrm{L})$} \\
\cline { 3 - 4 } & & -1 & 1 \\
\hline $\mathrm{x}_{1}$ & $\mathrm{FeSO}_{4} \cdot 7 \mathrm{H}_{2} \mathrm{O}$ & 0 & 0,1 \\
$\mathrm{x}_{2}$ & $\mathrm{MnSO}_{4} \cdot \mathrm{H}_{2} \mathrm{O}$ & 0 & 0,23 \\
$\mathrm{x}_{3}$ & $\mathrm{H}_{3} \mathrm{BO}$ & 0 & 0,4 \\
$\mathrm{x}_{4}$ & $\mathrm{CoCl}_{2} \cdot 6 \mathrm{H}_{2} \mathrm{O}$ & 0 & 0,01 \\
$\mathrm{x}_{5}$ & $\mathrm{CuSO}_{4} \cdot 5 \mathrm{H}_{2} \mathrm{O}$ & 0 & 0,01 \\
$\mathrm{x}_{6}$ & $\left(\mathrm{NH}_{4}\right)_{6} \mathrm{Mo}_{7} \mathrm{O}_{24}$ & 0 & 0,02 \\
$\mathrm{x}_{7}$ & $\mathrm{ZnSO}_{4}$ & 0 & 0,17 \\
$\mathrm{x}_{8}$ & $\mathrm{CaCl}_{2}$ & 0 & 0,2 \\
\hline
\end{tabular}

Table II presents the PB12 experimental matrix and the results of surface tension and biosurfactant concentration obtained in the different experimental conditions after 24 and 48 hours of fermentation. 
Table II: PB12 experimental matrix for each assay and their variables levels. Variables: $\mathrm{FeSO}_{4} \cdot 7 \mathrm{H}_{2} \mathrm{O}\left(\mathrm{x}_{1}\right), \mathrm{MnSO}_{4} \cdot 4 \mathrm{H}_{2} \mathrm{O}\left(\mathrm{x}_{2}\right)$, $\mathrm{H}_{3} \mathrm{BO}_{3}\left(\mathrm{x}_{3}\right), \mathrm{CuSO}_{4}\left(\mathrm{x}_{4}\right),\left(\mathrm{NH}_{4}\right)_{6} \mathrm{Mo}_{7} \mathrm{O}_{24}\left(\mathrm{x}_{5}\right), \mathrm{CoCl}_{2}\left(\mathrm{x}_{6}\right), \mathrm{ZnSO}_{4}\left(\mathrm{x}_{7}\right), \mathrm{CaCl}_{2}\left(\mathrm{x}_{8}\right)$, superficial tension (ST) and biosurfactant concentration (BC).

\begin{tabular}{ccccccccccccc}
\hline Assay & $\mathbf{x}_{\mathbf{1}}$ & $\mathbf{x}_{\mathbf{2}}$ & $\mathbf{x}_{\mathbf{3}}$ & $\mathbf{x}_{\mathbf{4}}$ & $\mathbf{x}_{\mathbf{5}}$ & $\mathbf{x}_{\mathbf{6}}$ & $\mathbf{x}_{\mathbf{7}}$ & $\mathbf{x}_{\mathbf{8}}$ & $\mathbf{S T}_{\mathbf{2 4 h}}(\mathbf{m N} / \mathbf{m})$ & $\mathbf{S T}_{\mathbf{4 8 h}}(\mathbf{m N} \mathbf{m})$ & $\begin{array}{c}\mathbf{B C}_{\mathbf{2 4 h}} \\
(\mathbf{m N} / \mathbf{m})\end{array}$ & $\begin{array}{c}\mathbf{B C}_{\mathbf{4 8 h}} \\
(\mathbf{m N} / \mathbf{m})\end{array}$ \\
\hline 1 & 1 & -1 & 1 & -1 & -1 & -1 & 1 & 1 & 29,1 & 29,6 & 137,3 & 223,0 \\
2 & 1 & 1 & -1 & -1 & -1 & 1 & -1 & 1 & 28,8 & 29,7 & 137,5 & 171,5 \\
3 & -1 & 1 & 1 & 1 & -1 & -1 & -1 & -1 & 29,7 & 30,0 & 88,1 & 125,4 \\
4 & 1 & -1 & 1 & -1 & 1 & 1 & -1 & -1 & 29,0 & 29,8 & 128,6 & 184,5 \\
5 & 1 & 1 & -1 & 1 & -1 & 1 & 1 & -1 & 28,7 & 29,6 & 163,0 & 224,0 \\
6 & 1 & 1 & 1 & 1 & 1 & -1 & -1 & 1 & 29,3 & 29,8 & 107,2 & 173,6 \\
7 & -1 & 1 & 1 & -1 & 1 & 1 & 1 & -1 & 28,5 & 29,5 & 117,1 & 132,2 \\
8 & -1 & -1 & 1 & 1 & -1 & 1 & 1 & 1 & 28,9 & 29,7 & 100,0 & 147,3 \\
9 & -1 & -1 & -1 & 1 & 1 & 1 & -1 & 1 & 28,7 & 29,0 & 104,9 & 146,8 \\
10 & 1 & -1 & -1 & 1 & 1 & -1 & 1 & -1 & 29,0 & 30,0 & 138,8 & 184,5 \\
11 & -1 & 1 & -1 & -1 & 1 & -1 & 1 & 1 & 28,8 & 30,0 & 155,1 & 197,1 \\
12 & -1 & -1 & -1 & -1 & -1 & -1 & -1 & -1 & 28,7 & 29,6 & 119,3 & 128,1 \\
\hline
\end{tabular}

At 24 and 48 hours of cultivation, the surface tension lowering values were similar for the 12 assays tested. This can be explained, since the biosurfactants are able to lower the surface tension to values close to $30 \mathrm{mN} / \mathrm{m}$ even at low concentrations in the culture medium, $[14 ; 15]$. Recent studies in the literature report that values of surface tension in the range obtained in this work indicate that the bioproduct may have efficient surfactant activity, even in contact with a complex mixture of hydrocarbons, such as crude oil. Fernandes et al [16] presented that the injection of $600 \mathrm{mg} / \mathrm{L}$ of biosurfactant resulted in approximately $69 \%$ recovery of residual oil in a glass column (Kontes Flex Column, Fisher Scientific K420401-2510) of 2.5x10 cm that remained after injection with water.

The maximum biosurfactant production in 24 hours was obtained in the assay $5(163 \mathrm{mg} / \mathrm{L})$, which increased $37 \%$ of the bioproduct concentration after 48 hours of fermentation $(224 \mathrm{mg} / \mathrm{L})$ with the decrease in productivity, as in all the other assays. Thus, taking into consideration the drop in productivity when using 48 hours of process, the further experimental planning were done with 24 hours of cultivation.

The model obtained for biosurfactant concentration after 24 hours of experiment is presented below:

$\mathrm{Y}_{\mathrm{BC} 24 \mathrm{~h}}=124,7+21,3 \mathrm{x}_{1}+6,5 \mathrm{x}_{2}-23,4 \mathrm{x}_{3}-15,5 \mathrm{x}_{4}+1,1 \mathrm{x}_{5}+$ $0,9 \mathrm{x}_{6}+21,0 \mathrm{x}_{7}-2,2 \mathrm{x}_{8}$.

The generated model was used to design a Pareto Diagram (Fig. 1), where it is possible to determine the variables with the highest statistical significance for the biosurfactant production.

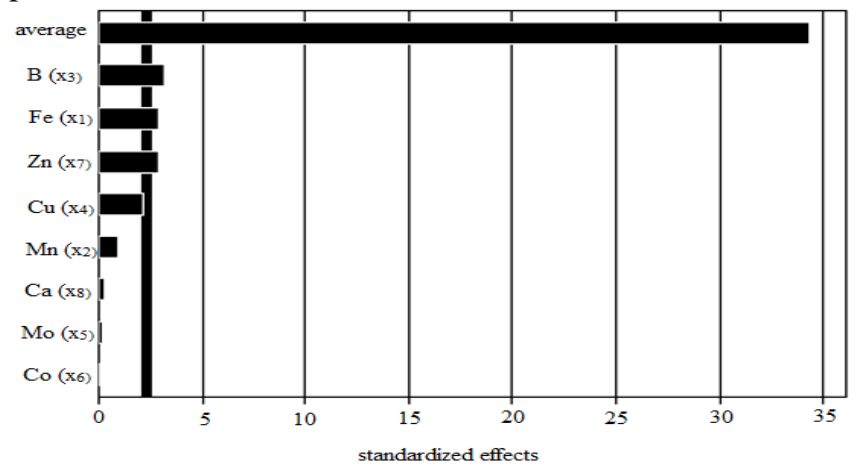

Fig. 1: Pareto Diagram for the experimental design PB12.
The obtained model indicates that the higher the coefficient value, the greater the impact of the change in the variable level, for the the evaluated response. Thus, for 24 hours fermentation, the highest coefficients for the biosurfactant concentration are obtained with the salts $\mathrm{FeSO}_{4} 7 \mathrm{H}_{2} \mathrm{O}$ and $\mathrm{ZnSO}_{4}$ in the production medium. The values associated with the elements $\mathrm{H}_{3} \mathrm{BO}_{3}, \mathrm{CuSO}_{4}$ and $\mathrm{CaCl}_{2}$ had negative effects on the biosurfactant production, this indicates that those salts can be considered as unnecessary for the biosurfactant production by the strain used, as well as all others that had lower coefficient values.

The results obtained in this sudy are in accordance with Wei et al. [17] with $\mathrm{Gu}$, et al [18]. The former studied the influence of the trace elements $\mathrm{Mn}^{2+}(0.2 \mathrm{mM})$ and $\mathrm{Fe}^{2+}(0.3$ $\mathrm{mM}$ ) in the mineral medium $4 \%$ glucose for the production of biosurfactant by Bacillus subtilis ATCC 21332 and concluded that the presence of one of the two metals is sufficient to allow efficient production of biosurfactant. The latter presented that $\mathrm{FeSO}_{4}(6.7879 \mu \mathrm{M})$ and $\mathrm{ZnSO}_{4}(0.0377$ $\mu \mathrm{M})$ were significant variables for lipopeptide production, iron being a common cofactor for microbial enzymes and proteins and therefore an essential mineral nutrient for microorganisms [19] and the addition of $\mathrm{ZnSO} 4$ to the growth of B. subtilis [20]. The results are also in agreement with Cooper, et al [20] and Abdel-Mawgoud, et al [21] who concluded that $\mathrm{Cu}^{+2}$ appears as a potent inhibitor of cell growth and biosurfactant production.

\section{CONCLUSION}

The present study showed the importance of Fe and $\mathrm{Zn}$ ions in the micronutrient solution added to the biosurfactant production medium by Bacillus subtilis LFB 732 strain. The qddition of the ions $\mathrm{Mn}, \mathrm{Ca}$, Mo and Co showed no influence.

On the other hand, the $\mathrm{B}$ and $\mathrm{Cu}$ ions showed a negative effect on the production. Thus, the elimination of some micronutrients from the production medium will not affect the yield of the process, in addition to reducing the costs of the bioproduct. 


\section{ACKNOWLEDGMENT}

The authors thank Laboratório de análise fitoquímica for the kindness of helping with de HPLC analysis.

\section{REFERENCES}

[1] M. Nitschke, S.G.V.A.O. Costa, "Biosurfactant in food industry". Trends in Food Science \& Technology, vol. 18, no. 5, pp. 252-259, 2007.

[2] S. Shekhar, A. Sundaramanickam, T. Balasubramanian, Biosurfactant "Producing Microbes and their Potential Applications: A Review". Environmental Science and Technology. vol. 45, n. 14, pp.1522-1554, 2015.

[3] D.W.F. Oliveira, I.W.L. França, A.K.N. Félix, J.J.L. Martins, M.E.A. Giro, V.M.M. Melo, L.R.B. Gonçalves, "Kinetic study of biosurfactant production by Bacillus subtilis LAMI005 grown in clarified cashew apple juice“. Colloids and Surfaces B: Biointefaces. vol. 101, no.1, pp. 34-43, 2013.

[4] M.M. Muller, J.H. Kugler, M. Henkel, M. Gerlitzki, B. Hormann, M. Pohnlein, C. Syldatk, R. hausmann, "Rhamnolipids- next generation surfactants?". Journal of Biotechnology . vol. 62, n. 4, pp. 366-380, 2012.

[5] C.N. Mulligan, "Environmental applications for biosurfactants". Environmental Pollution. vol. 133, pp. 183-198, 2004.

[6] S. DE, S. MALIK, A. GHOSH, R. SAHA, B. SAHA, "A review on natural surfactants". The Royal Society of Chemistry. vol. 5, pp. 65757-65767, 2015

[7] C. Syldatk, R. Hausmann, "Microbial Biosurfactants". European Journal of Lipid Science and Technology. vol. 112, n. 6, pp. 615-616, 2010.

[8] S. Maneerat, "Production of biosurfactants using substrates from renewableresources". Journal Science Technology. vol. 27, pp. 675-683, 2005

[9] C.P. Marin, J.J. Kaschuk, E. Frollini, M. Nitschke, "Potential use of the liquor from sisal pulp hydrolysis as substrate for surfactin production". Industrial Crops and Products. vol. 66, pp. 239-245, 2015.

[10] O.S. Amodu, S.K.O. Ntwampe, T.V. Ojumu, "Optimization of biosurfactant production by Bacillus licheniformis STK 01 grown exclusively on beta vulgaris waste using response surface methodology", BioResources. Vol. 9, n. 3, pp. 5045-5065, 2014.

[11] D.G. Cooper, J.E. Zajic, "Surface compounds from microorganisms". Advances in Applied Microbiology. vol. 26, pp. 229-256, 1980.

[12] R.S. Makkar, S.S. Cameotra, "Production of biosurfactantat mesophilic and thermophilic conditions by a strain of Bacillus subtilis". Journal of Industrial Microbiology and Biotechnology . vol. 20, pp. 48-52, 1998.

[13] Y.M. Wei, I.M. Chu, "Enhancement of surfactin production in iron-enriched media by Bacillus subtilis ATCC 21332”. Enzyme and Microbial Technology. vol. 22, pp. 724-728, 1998.

[14] C.N. Mulligan, "Environmental applications for biosurfactants". Environmental Pollution. vol. 133, pp.183-198, 2005.

[15] F.F.C. Barros, C.P. Quadros, M. R. Maróstica-Júnior, G.M. Pastore, "Surfactina: Propriedades químicas, tecnológicas e funcionais para aplicação em alimentos". Química Nova. vol. 30, n. 2, pp. 409-414, 2007.

[16] P.L. Fernandes, E.M. Rodrigues, F.R. Paiva, B.A.L. Ayupe, M.J. McInerney, M.R. Tótola, "Biosurfactant, solventes and polymer production by Bacillus subtilis RI4914 and their application for enhanced oil recovery". Fuel. vol. 180, pp. 551-557, 2016.

[17] Y.M. Wei, C.C. Lai, J.S. Chang, "Using Taguchi experimental design methods to optimize trace element composition for enhanced surfactin production by Bacillus subtilis ATCC 21332". Process Biochemistry. vol. 42, pp. 40-45, 2007.

[18] X.B. Gu, Z.M. Zheng, H.Q. Yu, J. Wang, F.L. Liang, R.L. Liu, "Optimization of medium constituents for a novel lipopeptide production by Bacillus subtilis MO-01 by a response surface method". Process Biochemistry. Vol. 40, pp. 3196-3201, 2005.

[19] R.M. Batista, R.D. Rufino, J.M. Luna, J.E.G. Souza, L.A. Sarubbo, "Effect of medium components on the production of a biosurfactant from Candida tropicalis applied to the removal of hydrophobic contaminants in soil". Water Environment Research. vol. 82, n 5, pp. 418-425, 2010.

[20] D.G. Cooper, C.R. Macdonald, S.J.B. Duff, N. KosariC, "Enhanced production of surfactin from Bacillus subtilis by continuous product removal and metal cation additions". Applied And Environmental Microbiology. vol. 42, n. 3, pp. 408- 412, 1981.

[21] A.M. Abdel-Mawgoud, M.M. Aboulwafa, N.A.H. Hassouna, "Optimization of surfactin production by Bacillus subtilis isolate BS5". Applied Biochemistry Biotechnology. vol. 150, pp. 305-325, 2008

Mariana Ruiz Frazão Santiago holds a bachelor's degree in Chemical Engineering from the Universidade Federal do Rio de Janeiro (UFRJ) (2010), a Master's Degree from the Program of Tecnologia de Processos Químicos e Bioquímicos at UFRJ (2014) and is currently a doctor in science student at Universidade Federal do Rio de Janeiro. Mariana has experience in the development of Bioprocesses, fermentative processes and biosurfactant production.

Vitor da Silva Liduino holds bachelor's degree in Biological Science Biológicas: Microbiology e Immunology from Universidade Federal do Rio de Janeiro (UFRJ) (2011), Master's Degree from Universidade Federal do Rio de Janeiro (2013) and a Doctor of Science Degree (D.Sc.) from Universidade Federal do Rio de Janeiro (2018). Has experience in Microbiology, focusing on Applied Microbiology, acting on the following subjects: biocorrosion, BRS, phitoremediation, biofilm and carbon- steel.

Lizeth Jaramillo holds a bachelor's degree in Chemical Engineering from the Universidad Industrial de Santander (2010), a Master's Degree from the Program of Tecnologia de Processos Químicos e Bioquímicos at UFRJ (2014) and is currently a doctor in science student at Universidade Federal do Rio de Janeiro. Lizeth has experience in the area of Chemical Engineering, with emphasis on Bioprocess. Focused, mainly, in the subjects: lactic acid, fermentative processes, biomass and sustainability.

Paula Fernandes de Aguiar holds a bachelor's degree in Chemistry from Universidade Federal do Rio de Janeiro (1987), master's in Chemistry from Universidade Federal do Rio de Janeiro (1991) and doctorate in Pharmacy from Vrije Universiteit Brussel (1997). MBA in Quality from COPPE/BVQI. Paula has experience in Chemistry and Metrology, acting on the following subjects: analytical chemistry, pharmacy and petroleum.

Maria Aparecida de Melo holds a bachelor's degree in Metallurgical Engineering by Universidade Federal de Ouro Preto (1984), master's in Petroleum Engineering by Universidade Federal de Ouro Preto (1987) and Ph.D. at Science and Technology of polymers by Universidade Federal do Rio de Janeiro (2008) . Currently is of Centro de Pesquisa e Desenvolvimento Leopoldo Américo Miguêz de Mello. Focused, mainly, in the subjects: hondsoluble polymers.

Eliana Flávia Camporese Sérvulo holds a bachelor's degree in Chemical Engineering from the Universidade Federal do Rio de Janeiro (UFRJ) (1979), a Master's Degree from the Program of Engenharia de Processos Químicos e Bioquímicos at UFRJ (1983) and Doctor in Sciences (Microbiology) also from UFRJ (1991). Eliana is currently associate professor at UFRJ. She has experience in Chemical Engineering, working mainly on the following topics: bioremediation, phytoremediation biocorrosion, mitigation of biogenic $\mathrm{H}_{2} \mathrm{~S}$ generation, bioleaching, and bioproducts (biosurfactants, biopolymers, natural pigments and organic acids). 